\title{
Efficiency relationship of LED parameters in solid state lighting
}

\author{
Mehmet Sait Cengiza,* \\ a Bitlis Eren University, Department of Technical Vocational School, TR-13000, Bitlis Turkey
}

ART ICLE INFO

\section{Article history:}

Received 05 November 2018

Received in revised form 18 April 2019

Accepted 24 April 2019

Keywords:

LED, lighting

CRI

CCT

Solid state

\begin{abstract}
A B S T R A C T
In this study the power, power factor, correlated color temperature (CCT), color rendering index (CRI), lux values measured from $0.75 \mathrm{~m}$ distance, LED lamp temperatures and changes in the currents of 6 LED lamps, which are most commonly used and directly connected to the network are experientially recorded. The effects seen from the very start and 1 hour later, on LED lamps were compared in terms of temperature, current, and lux values. The high temperature values on the LED were seen to have adverse effects on the efficiency of the LED lamp.
\end{abstract}

\section{Introduction}

Man learned to use artificial light with the discovery of fire. He then used torches and oil lamps as artificial light. The oil lamp, torch and candle had been important light sources until the mid-19th century. Understanding of lighting changed in 1870 s when Edison developed a filament lamp. In 20th century, fluorescent lamps and discharge lamps were used. At the end of the 20th century, solid state semiconductor LED lamps were used as artificial light sources in lighting. In artificial light production, heating method is used to convert electrical energy to light, discharge method and luminescence methods are used in low and highly pressured metal vapor environment.

- Heating method: Electric current is passed through a filament structure to warm up the filament. Through the light sight from the current incandescent filament is provided with vision. Both the incandescent lamp and the halogen lamps are in this group.

- Gas discharge: By applying voltage in a deflated tube with metal vapor through two electrodes, the light emitted by the current is used for illumination and vision. Any type of mercury vapor, metal and sodium vapor lamps are included in this group $[1,2]$.

- Luminescence: Visible light is obtained in the low-pressured mercury vapor lamps by stimulating the phosphor layer with invisible UV light. Fluorescent lamps and compact fluorescent lamps are included in this group. As a method of directly converting the electrical by stimulating light electrons known as electroluminescence in a solid form, illumination and vision are provided. LED lamps are the best example of this.

In solid state lighting, LED lamps are used as artificial light sources in lighting. It emits light when the electric current passes through the LED. The electric current gives brightness as it passes through a diode. The electrical current emits light through the phosphor layer on the LED diode. According to this layer, the light quality or color temperature is adjusted. Multiple diodes are used to create the LED lighting array. This allows more light. The LEDs emit light in one direction. Lighting engineers use special diffusers and optics to soften the light from the diode and spread evenly in all directions. LEDs provide advantages in terms of ease of control and efficiency. There are many energy efficiency, micro grids and sensor based simulation studies prepared in this direction [3-6]. In addition, artificial neural networks are used in many studies to reduce energy consumption in recent years [7-10].

\section{The general structure of the LEDs}

The word LED is formed by the abbreviation of the "Light Emitting Diodes". By its design, a LED chip is an optoelectronic element consisting of the active layer and the electrical connections compressed between the $\mathrm{N}$ and $\mathrm{P}$ type semiconductor layers. When the current passes through the LED in the right direction, illumination is provided by stimulating the light emitting active layers. The light produced 
directly and indirectly from the reflectors allows to see. The LED chip structure is shown in Figure 1.

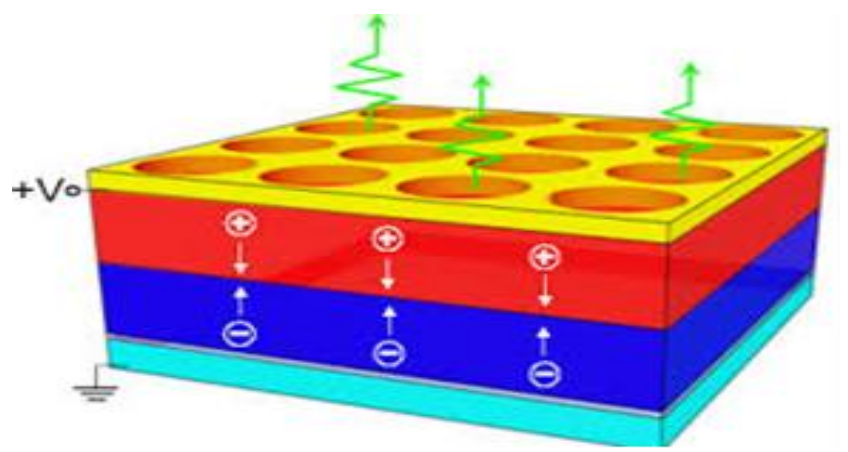

Figure 1. LED chip structure

LED lighting products emit light depending on the active layer in the blue-yellow light layer shown in Figure 1. This light emits light according to the type and properties of the material used in the active layer while spreading. In other words, monochrome light is produced according to the type of material with the effect of active layer in LED lighting $[11,12]$. In colored LEDs emitting light at high level, different materials are used as active layer (GaAs, Gap, GaN, AlInGaP and InGaN). Producing white light with LEDs is possible in two ways. The first method is to obtain white light by using three LED chips in red, green and blue color. The second one is to produce white light by stimulating a phosphor layer of light produced in the blue LED chip.

The main reason for using LED light source in lighting is energy efficiency. It is possible to minimize optical losses and armature losses if LEDs have high light efficiency and are well planned. Different durations of LEDs can be calculated depending on the armature structure, type of usage and the place of use of LEDs. In some cases, LEDs can work up to 15,000 hours, in some cases up to 100,000 hours. Compared to 1000 hour- incandescent lamp, 2000 hour-halogen lamp, 2.00015.000 hour- CFL and Fluorescent lamps' life span; LEDs can be used for a much longer time [13-15]. The Figure 2 shows operating life of various lamps.

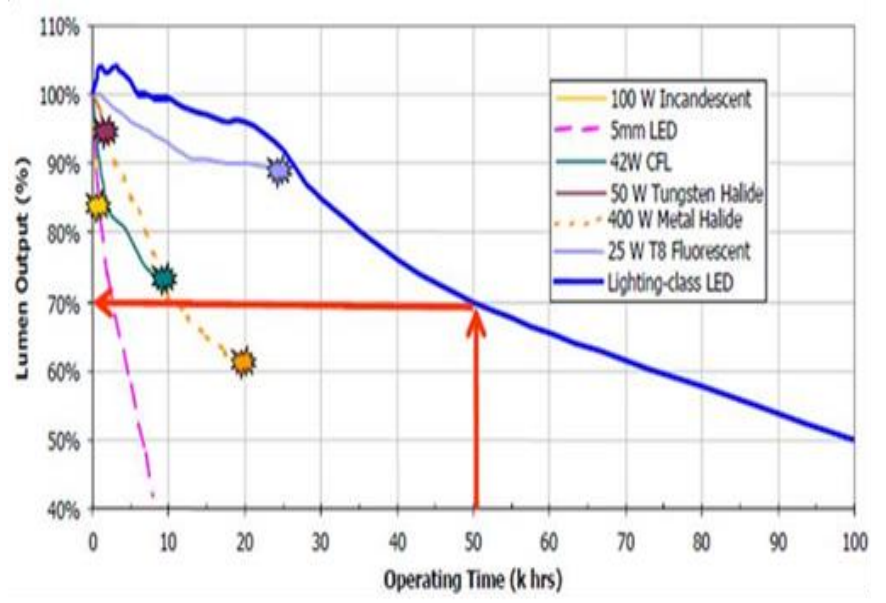

Figure 2. Operating life of various lamps

When LEDs are given energy, they react very fast and reach the maximum light level. For this reason, the use of LEDs in brake lamps increased to improve the driving safety. As LEDs do not contain IR light, they do not heat the objects and areas they illuminate. So, heat-induced losses are low. Structurally, glass, filament, etc. are more physically resistant to shocks and vibrations as they do not contain fragile pieces. When they work with right current or if they work with pulsed current that is higher than the mains frequency, they produce vibration-free light [16, 17]. Due to their mode of light production, the physical sizes, that is, the volumes they cover, are small. The light coming out of LEDs illuminates by being directed from single point. Thanks to LEDs, it is possible to obtain the desired light beam and angles with the optical systems. The fact that LEDs have long life span and are small means less environmental waste. The fact that LEDs do not contain mercury is an important feature in terms of environmentalist approach. In addition to switching on and off, vibration free dimming is the most important feature of LEDs [18]. They can be dimmed $0-100 \%$ seamlessly with right mechanisms. When dimming there is no color shift.

\subsection{Electrical properties}

LEDs work with the right current. In electrical circuits, LEDs behave like normal diodes. The difference is that instead of a junction voltage of around 0.7 volts in normal diodes, they operate at voltages between 1.6 and 4 volts, depending on their color. Generally, red and yellow LEDs operate at 1.9-2.6 V, green blue and white LEDs operate at voltages between $2.5-4 \mathrm{~V}$. LED currents vary between $10-700 \mathrm{~mA}$ depending on the structure. They vary with a non-linear curve depending on the magnitude of the current passing through the LED impedances.

The LEDs are usually connected in series and are fed with electronic power sources which generate 10,12, 24, $48 \mathrm{~V}$ direct current by creating an index. Electronically controlled power supplies need to be used to operate LEDs [19]. 350-700 mA current-controlled power supplies are used for LEDs.

In many applications, it is requested that the intensity of the light emitted by the LED is as high as possible. As the light intensity obtained from LEDs is proportional to the current passing through it, the light intensity will increase as the current is increased. In this case, the heat generated will increase due to the internal resistance of the LED and it will get damaged before the normal service life span ends [20]. In addition, the increase in heat will affect the light efficiency adversely. Accordingly, when a current of $25 \mathrm{~mA}$ is applied to a $20 \mathrm{~mA}$ LED, high level of light values can be obtained, but the LED's life is shortened.

\subsection{The advantages of LEDs}

- No color separators are required for monochrome light. A traffic light with a red color shows a $617 \mathrm{~nm}$ wavelength value. The light generated at the red light with a wavelength of 617 $\mathrm{nm}$ is used. In the case of incandescent lamps there is a different situation. Blue and green components are pressed from the light produced in incandescent lamps and the red component is dominated. Thus $80 \%$ energy is saved by using a $10 \mathrm{~W}$ LED array instead of a $75 \mathrm{~W}$ incandescent lamp.

- Very small light source: Small size armatures are developed, light can easily be directed.

- They provide designers with broad and easy use opportunity 
- Their reaction rates are high, they start to illuminate within 200 ns.

- LEDs are long-lasting, operating up to 100.000 hours depending on usage.

- They provide high light efficiency.

- They have low heat production. The filament temperature in incandescent lamps is $2700{ }^{\circ} \mathrm{C}, 3100{ }^{\circ} \mathrm{C}$ in halogen lamps, the tube temperature in discharged lamps reaches $800-1100{ }^{\circ} \mathrm{C}$, while chip heat in LEDs does not reach $110^{\circ} \mathrm{C}$.

- Almost all colors with visible color spectrum can be obtained.

- They are dimmable.

- They are resistant to shocks and vibrations. They do not contain fragile elements such as glass, filaments.

- The LED lamps are easy to adapt to smart meters or smart grids. LEDs are suitable for remote monitoring, automation and data exchange with wireless sensor networks $[21,22]$.

Theoretical calculations and experiments show that LEDs can be used for up to 100.000 hours. Considering electrical, thermal condition (cooling), environmental effects, environmental elements used, material structure of sheath, etc. LEDs can be used over 100.000 hours.

\subsection{The efficiency of a LED}

Efficiency is the most important problem to be solved in the energy field. Many studies in the field of energy are used to increase energy efficiency. LED lamps are distinguished by their energy efficiency compared to the classic lamps [23, 24].

Monochrome light sources (narrowband): Since the light is in the corresponding wavelength range, color separators such as color filter or prism are not needed. For example, in a red traffic light, the whole. The ratio of the light emitted by lamps to the electric energy consumed is expressed as the light efficiency. Its unit is the lumen/Watt. Lumen/Watt values for different light sources [25];

- The luminous efficiency in incandescent lamps is $12-15$ $\operatorname{lm} / \mathrm{W}$,

- For halogen lamps, 18-22 lm/W,

- For compact fluorescent lamps: $60 \mathrm{~lm} / \mathrm{W}$,

- Fluorescent lamps: 55-104 lm/W

The lumen/watt values for LEDs vary according to the LED's color. The red color has the highest efficiency of $60 \mathrm{~lm} / \mathrm{W}, 55$ $\mathrm{lm} / \mathrm{W}$ for yellow $35 \mathrm{~lm} / \mathrm{W}$ for green and $18 \mathrm{~lm} / \mathrm{W}$ for blue. White light is the most important color used in lighting. The efficiency for white LED is around $85 \mathrm{~lm} / \mathrm{W}$ depending on the manufacturer and the light efficiency is increasing day by day.

One thing to be aware of about LED light values is light angles. Since the LEDs are directed lights, the light values are given in candela. One of the important things in solid-state lighting is the changing of the angle of the light, directing it, distributing it with a light guide, briefly using the light produced by the LED. LEDs are a single color light source. While single color can be used in decorative lighting, intermediate colors can be obtained by mixing colorful LED lights. For this, LED arrays consisting of three main colors (red, green, blue) are dimmed.
Theoretically, if each color is DIMMED by 255 steps (third power of 255) 16 million colors can be obtained.

LEDs used when creating LED array should have the same or similar wave length. Differences of 5-10 nm are especially perceived by the eye in green and yellow colors [14]. For projects where colors are important, LEDs with low color tolerance should be used. Another issue regarding color is the use of colored lenses in front of LED arrays. Here, the wavelength of LED and colored lens should be the same. Otherwise it will cause color loss. The components of the LED lamp are shown in Figure 3.

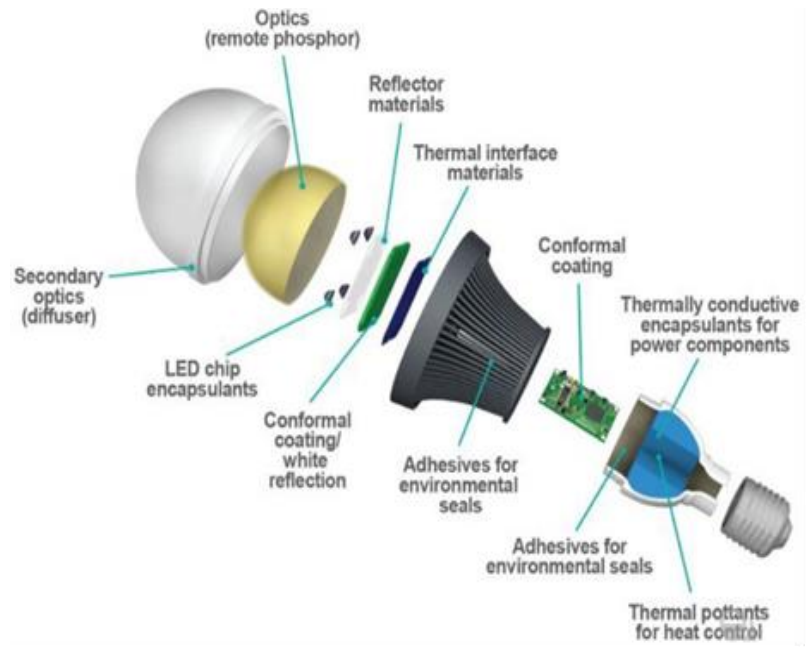

Figure 3. LED chip structure LED lamp components

The life span of LEDs is determined by the time it takes for the initial light power to drop to $70 \%$. Therefore, the fact that LED's life span is 50.000 hours for example, does not mean that the life span of a solid-state lighting unit using this LED will be 50.000 hours. The advantages such as long lifespan of a LED or high LED efficiency $(\mathrm{lm} / \mathrm{W})$ cannot always reflected directly to the LED lamp. Because besides the LED module, there are mechanical and optical system, cooler, driver and dimmer within the lamp. The reliability of the solid-state lighting unit will depend on the reliability of all these subsystems, all together and their life span will be determined by the life span of the shortest-lived component depending on the life span of the weakest link in this chain [8-17]. As seen in Figure 4, the causes for most of the failures in solid state lighting units with LEDs are power sources, namely LED drivers.

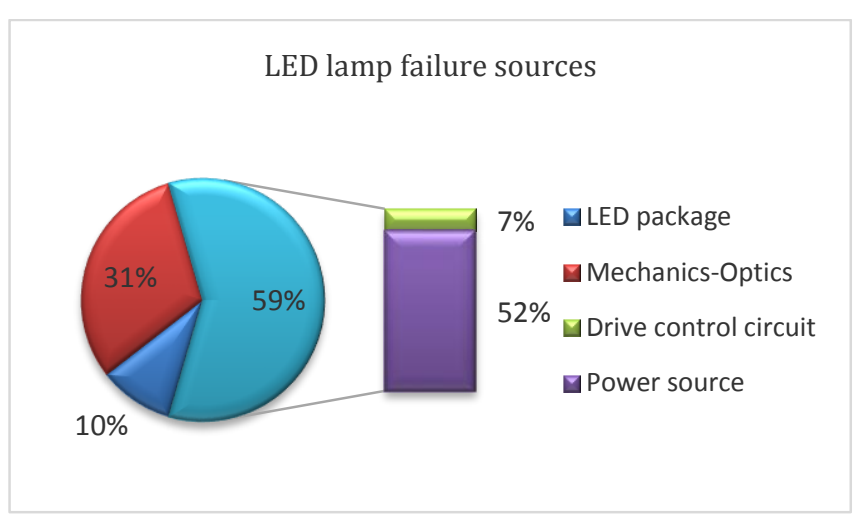

Figure 4. Failure causes within LED solid state lighting units 


\section{Results and Discussion}

In this study the power, power factor, CCT, CRI, lux values measured from $0.75 \mathrm{~m}$ distance, LED lamp temperatures and changes in the currents of the 6 LED lamps, which are most commonly used and directly connected to the network are experientially recorded. The effects seen from the very start and 1 hour later on the LED lamps were compared in terms of temperature, current, and lux values.

In the study, light measurements were made with an LED spectrometer and temperature measurements were made with an infrared thermometer. Table 1 shows the measured values of various LED lamps.

Table 1. Measurement values of various LED lamps

\begin{tabular}{|c|c|c|c|c|c|c|c|}
\hline \multicolumn{2}{|c|}{ Brand } & 1 & 2 & 3 & 4 & 5 & 6 \\
\hline \multicolumn{2}{|c|}{ Power } & 10.4 & 10.3 & 10.2 & 9.4 & 9.3 & 10.5 \\
\hline \multicolumn{2}{|c|}{ Power Factor } & 0.65 & 0.68 & 0.95 & 0.59 & 0.6 & 0.65 \\
\hline \multicolumn{2}{|c|}{$\mathrm{CCT}$} & 2880 & 3034 & 6333 & 2732 & 2951 & 2989 \\
\hline \multicolumn{2}{|c|}{ CRI } & 81 & 82 & 81 & 81 & 81 & 81 \\
\hline \multirow{3}{*}{ 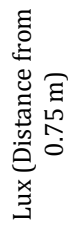 } & At first & 345 & 465 & 174 & 332 & 305 & 291 \\
\hline & $\begin{array}{l}\text { After } \\
1 \text { hour }\end{array}$ & 302 & 441 & 142 & 291 & 252 & 244 \\
\hline & Lost \% & $12.46 \%$ & $5.16 \%$ & $18.39 \%$ & $12.35 \%$ & $17.38 \%$ & $16.15 \%$ \\
\hline \multirow{2}{*}{$\begin{array}{l}\stackrel{0}{\Xi} \\
\stackrel{\Xi}{0} \\
\stackrel{0}{0} \\
\stackrel{\Xi}{\Xi} \\
\stackrel{0}{\bullet}\end{array}$} & At first & 23 & 23 & 23 & 23 & 23 & 23 \\
\hline & $\begin{array}{l}\text { After } \\
\text { 1hour }\end{array}$ & 94 & 85 & 93 & 105 & 91 & 91 \\
\hline \multirow{3}{*}{$\begin{array}{l}\stackrel{\vec{z}}{0} \\
\stackrel{\Xi}{\Xi}\end{array}$} & At first & 0.074 & 0.070 & 0.050 & 0.071 & 0.070 & 0.072 \\
\hline & $\begin{array}{l}\text { After } \\
1 \text { hour }\end{array}$ & 0.072 & 0.070 & 0.047 & 0.069 & 0.066 & 0.067 \\
\hline & Lost $\%$ & $2.13 \%$ & $0.00 \%$ & $5.10 \%$ & $3.04 \%$ & $4.73 \%$ & $7.53 \%$ \\
\hline
\end{tabular}

As seen in Table 1, the LED lamp Brand-3 is the most prominent in terms of power factor and CCT values, and all LED lamps are equivalent in terms of CRI. Examining Table 1, the LED lamps were energized when the initial temperature of the environment where test was conducted was $23{ }^{\circ} \mathrm{C}$. Later, measurements were made again on LED lamps working for 1 hour. It has been seen that out of 6 LED lamps, the LED lamp which was heated up to the acceptable limit values was the LED lamp named Brand- 2 .

The body temperature of other lamps increased to $91-105^{\circ} \mathrm{C}$. Therefore, it has been seen that 5 lamps except for the Brand2 cannot perform the cooling process successfully.

Accordingly, there are variations in the lux values measured from $0.75 \mathrm{~m}$ distance from the very start and 1 hour later. The amount of light emitted by LED lamps has dropped by 5.16 even in Brand-2 which has reached the $85{ }^{\circ} \mathrm{C}$ temperature which is considered successful. However, in other LED lamps, the amount of light dropped by $12.35 \%-17.38 \%$. The adverse effect of heat on the efficiency of the LED lamp is clearly seen here. The efficiency loss of LED lamps heating up to $91{ }^{\circ} \mathrm{C}$ and above is $12.35 \%$ and more.

\section{Conclusions}

Considering the long operating life span and high efficiency levels of LEDs, it is understood that significant savings can be achieved in the amount of energy consumed for lighting in the World, if these potential advantages of LEDs solid state lighting units formed by using the LED modules can be used appropriately.

As seen from Table 1, if LEDs are not cooled down properly, their voltage values decrease accordingly, which reduces the power of the LED lamp. Therefore, the total light flux decreases due to the increasing heat. Accordingly, the vision comfort in the living areas decreases in proportion to the total light flux.

\section{References}

[1] Cengiz M.S., 2019. A Simulation and Design Study for Interior Zone Luminance in Tunnel Lighting, Light \& Engineering, 27(2), 42-51.

[2] Cengiz M.S., 2019. The Relationship Between Maintenance Factor and Lighting Level in Tunnel Lighting, Light \& Engineering, 27(3).

[3] Çıbuk M., Arı D., Çınar H. 2016. A new multi-channel algorithm of join the network for single hop multi-node sensor networks, International Engineering, Science and Education Conference, 01-03 December 2016, Diyarbakir/Turkey

[4] Arı D., Çıbuk M., Ağgün F., 2017. Effect of relay-priority mechanism on multi-hop wireless sensor networks, Bitlis Eren University Journal of Science and Technology, 7(2), 145-153

[5] Maraşlı F., Çıbuk M., 2016. RFID based on the design of a new fuel recognation system, Bitlis Eren Univ J Sci \& Technology,6 (2), 66-72.

[6] Efe SB., 2015. Harmonic Filter Application for an Industrial Installation, IEEE The 13th International Conference on Engineering of Modern Electric Systems 11-12 June 2015, Oradea, Romania.

[7] Ertugrul, Ö.F. 2018. Two Novel Versions of Randomized Feed Forward Artificial Neural Networks: Stochastic and Pruned Stochastic Neural Processing Letters 48 (1), 481-516.

[8] Efe, S.B., Cebeci, M., 2015. Artificial Neural Network Based Power Flow Analysis for Micro Grids. Bitlis Eren University Journal of Science and Technology, 5(1), 42-47.

[9] ] Ertugrul, Ö.F., Kurt, M.B. 2014. A Fast and Accurate Fault Detection Approach in Power Transmission Lines by Modular Neural Network and Discrete Wavelet Transform, Computer Science and Applications 1 (3), 152-157.

[10] Ertugrul, Ö.F., Kaya, Y. 2016. Smart city planning by estimating energy efficiency of buildings by extreme learning machine 20164 th International Istanbul Smart Grid Congress and Fair (ICSG), 1-5.

[11] Laurentin, C., Berruto, V. and Fontynont, M., 2000. Effect of thermal conditions and light source type on visual comfort appraisal. Lighting Research \& Technology 4: 223-233.

[12] Yurci Y., Yıldırım S., Palta O., Cengiz Ç., Atiç S., Yapıcı İ., Cengiz M.S., and Eren M., 2017. Numerical analysis of LED illumination productivity parameter, International Conference on Multidisciplinary, Engineering, Science, Education and Technology Imeset'17 Baku Book Of Abstracts, July 12-14, 2017, pp 10, Bakü.

[13] Ronchi, L., 2009. On the variability of visual functionality across the day, Light \& Engineering, 4: 25-33.

[14] Boyce, P.R., 2006. Lemmings, light health, Light \& Engineering, 2: 24-31. 
[15] Cengiz C.., Kaynaklı M., Gencer G., Eren M., Yapıcı İ., Yıldırım S., and Cengiz M.S., 2017. Selection Criteria and Economic Analysis of LEDs, International Conference on Multidisciplinary, Engineering, Science, Education and Technology Imeset'17 Bitlis Book Of Abstracts, October 27-29, 2017, pp 230, Bitlis.

[16] Figueiro, M.G., Rea, M.S., 2011. Sleep opportunity and periodic light exposure of biomakers performance, Lighting Research \& Technology, 2: 349-369.

[17] Veitch, J. 2005. Lighting and Health: issues for consideration, Light \& Engineering, 4: 6-13.

[18] Fuller, S., and Carrasco, M., 2006. Exogenous attention and colour perception: performance and appearance saturation, Vision Research, 2; 4032-4047.

[19] Brainard, G.C., Provencio, I., 2008. Photoreception for the neurobehavioral effects of light in humans, Light \& Engineering, 1:518.
[20] LED Luminaire. 2011. http://apps1.eere.energy.gov/buildings/ publications/pdfs/ssl/led_luminaire-lifetime-guide_june2011.pdf, (03.12.2018)

[21] Cengiz, M.S. (2014) Evaluation of Smart Grids and Turkey. Global Advanced Research Journal of Engineering Technology and Innovation, 3(7), 149-153.

[22] Cengiz, M.S. (2013) Smart meter and cost experiment. Przeglad Elektrotechniczny, 89(11), 206-209.

[23] Cengiz, M.S. Mamiş M.S. (2015) Endüstriyel tesislerde verimlilik ve güneş enerjisi kullanımı. VI. Enerji Verimliliği Kalitesi Sempozyunu ve Sergisi, 21-25. 4-6 Haziran 2015, Sakarya, Türkiye

[24] Cengiz, M.S. Mamiş M.S. (2015) Solution Offers For Efficiency and Savings in Industrial Plants. Bitlis Eren University Journal of Science and Technology 5(1), 24-28.

[25] Emergency Lighting Unit Solutions, www.besa-electronic-urunkata logu.pdf, (27.02.2018) 